\title{
1 A novel ultrasound-guided mouse model of sudden cardiac arrest
}

2 Cody A. Rutledge ${ }^{1}$, Takuto Chiba ${ }^{2,3}$, Kevin Redding ${ }^{1}$, Cameron Dezfulian ${ }^{4}$, Sunder Sims-Lucas ${ }^{2,3}$, Brett A.

3 Kaufman $^{1}$

5 1. Division of Cardiology, Cardiovascular Institute, University of Pittsburgh, Pittsburgh, PA, USA

6 2. Rangos Research Center, Children's Hospital of Pittsburgh, University of Pittsburgh, Pittsburgh, PA, 7 USA

8 3. Division of Nephrology, Department of Pediatrics, University of Pittsburgh School of Medicine, 9 Pittsburgh, PA, USA.

10 4. Safar Center for Resuscitation Research and Critical Care Medicine Department, University of 11 Pittsburgh, Pittsburgh, PA, USA

12

13 Corresponding Author:

14 Brett Kaufman (bkauf@pitt.edu) 


\section{Abstract}

17 Aim: Mouse models of sudden cardiac arrest are limited by challenges with surgical technique and 18 reliable venous access. To overcome this limitation, we sought to develop a simplified method in the mouse that uses ultrasound-guided injection of potassium chloride directly into the heart.

20 Methods: Potassium chloride was delivered directly into the left ventricular cavity under ultrasound 21 guidance in intubated mice, resulting in immediate asystole. Mice were resuscitated with injection of

22 epinephrine and manual chest compressions and evaluated for survival, body temperature, cardiac

23 function, kidney damage, and diffuse tissue injury.

24 Results: The direct injection sudden cardiac arrest model causes rapid asystole with high surgical survival 25 rates and low surgical duration. Sudden cardiac arrest mice with 8-min of asystole have significant 26 cardiac dysfunction at 24 hours and high lethality within the first seven days, where after cardiac 27 function begins to improve. Sudden cardiac arrest mice have secondary organ damage, including 28 significant kidney injury, but no clear evidence of neurologic dysfunction.

29 Conclusions: Ultrasound-guided direct injection of potassium chloride allows for rapid and reliable 30 cardiac arrest in the mouse that mirrors human pathology. This technique lowers the barriers to entry 31 for adoption of the mouse model of sudden cardiac arrest, which will improve investigators' ability to 32 study the mechanisms underlying post-arrest changes. 


\section{Introduction}

34 Out of hospital cardiac arrest affects over 350,000 patients annually in the United States ${ }^{1}$. Only $10 \%$ of these patients will survive to hospital discharge and only $6 \%$ of the patients will be discharged with a favorable outcome ${ }^{2,3}$. These statistics suggest a dramatic need for novel interventions to improve cardiac arrest outcomes. Numerous animal models of sudden cardiac arrest (SCA) have been developed to help understand the mechanisms underlying cardiac arrest mortality and to explore potential interventions in pre-clinical models ${ }^{4,5}$. A review of animal models of SCA found that only $6 \%$ of preclinical SCA studies were completed in mice ${ }^{5}$. A mouse model has a number of advantages over large animal models, including rapid breeding, cost-effectiveness, and opportunity for genetic manipulation. ${ }^{6}$ However, mouse use to model SCA has been limited by difficulty obtaining venous access and delivering

43 life support related to the animal's size ${ }^{7,8}$.

44 The major limitation to adoption of the mouse model is the difficult cannulation of the delicate femoral 45 or internal jugular (IJ) veins, resulting in prolonged surgical times and high lethality. Moreover, venous 46 cannulation requires ligation of the vessel post-operatively, which may further contribute to organ 47 damage and alter outcomes. In this paper, we describe a novel method for ultrasound-delivery of 48 potassium chloride (KCl) directly into the left ventricle (LV) to induce immediate cardiac arrest, 49 bypassing the need for establishing intravenous access. This direct cardiac injection method simplifies 50 the surgical process, lowering the barrier to entry for this model. Our model has rapid procedure times 51 and high rate of surgical survival, thereby increasing the opportunity for study of preventative and 52 therapeutic interventions, as well as mechanistic aspects of organ damage and recovery. 


\section{Methods}

\section{Animal Preparation}

8-week-old C57BL/6J male and female mice were anesthetized using $5 \%$ isoflurane in $100 \%$ oxygen via induction box until reaching the surgical plane. These mice were placed in a supine position and intubated by $22 \mathrm{~g}$ catheter and mechanically ventilated (MiniVent, Harvard Apparatus, Holliston, MA) at a rate of $150 \mathrm{bpm}$ ( $125 \mu \mathrm{L}$ for females and $140 \mu \mathrm{L}$ for males). Animal temperature was maintained near $37^{\circ} \mathrm{C}$ via heating pad and rectal temperature probe and heart rate (HR) was monitored continuously using surface electrocardiogram (ECG; Visual Sonics, Toronto, Canada). HR was maintained between 400-500 bpm by adjusting isoflurane concentration. Depilatory cream was applied to the thorax and the chest cleaned with alcohol. All studies were performed at the University of Pittsburgh in compliance with the National Institutes of Health Guidance for Care and Use of Experimental Animals and was approved by the University of Pittsburgh Animal Care and Use Committee (Protocol \#18032212).

\section{Ultrasound-guided KCl Delivery and Cardiopulmonary Resuscitation (CPR).}

Baseline transthoracic echocardiography was performed using the Vevo 3100 imaging systems (Visual Sonics) with a $40 \mathrm{MHz}$ linear probe along the long-axis of the heart. A 30-gauge needle was carefully advanced under ultrasound-guidance through the intercostal space and directed into the LV (Figure 1A). $40 \mu \mathrm{L}$ of $0.5 \mathrm{M} \mathrm{KCl}$ in saline was delivered into the LV cavity, causing immediate asystole on ECG. The ventilator was turned off at this time. Doppler imaging was utilized over the aortic outflow tract to confirm that no blood was ejected during asystole. The mice remained in asystole for 7.5 minutes, when a second 30-gauge needle was introduced into the LV and $500 \mu \mathrm{L}$ of $15 \mu \mathrm{g} / \mathrm{mL}$ epinephrine in saline was delivered over approximately 30 seconds. At 8 minutes, the ventilation was resumed at $180 \mathrm{bpm}$ and CPR initiated. CPR was performed manually at $300 \mathrm{bpm}$ for $1 \mathrm{~min}$, at which time CPR was briefly held and ECG evaluated for recovery of spontaneous circulation (ROSC). If a ventricular rhythm was observed on ECG, doppler imaging was performed to confirm blood flow. If not, one to two additional 1-minute cycles of CPR were performed. Animals not achieving ROSC by 3 minutes were euthanized. Mice remained on the ventilator (without isoflurane) for approximately 20-25 minutes until breathing spontaneously at a rate over 60 respirations/minute. Sham mice received no $\mathrm{KCl}$ injection, but did receive a single direct $\mathrm{LV}$ injection of $500 \mu \mathrm{L}$ epinephrine and were extubated immediately after injection. All animals were placed in a recovery cage under heat lamp for 2 hours with hourly temperature monitoring for up to 4 hours. Survival was assessed every morning for a 4 -week survival cohort.

Figure 1. Direct LV Injection Model of SCA. A) Representative long-axis ultrasound image depicting introduction of a needle into the LV chamber. B) Representative ECG tracings at baseline, during $\mathrm{KCl}$ injection, during asystole, immediately after ROSC is achieved, and during recovery. C) Depiction of time course of SCA in this model. D) Temperature monitoring in sham and arrest mice at baseline, time of ROSC, and at 1, 2, 3, 4 and 24 hours post ROSC. Arrest mice have significanly depressed body temperature at 3, 4, and 24 hours after arrest when compared to sham mice. E) Mortality curve demonstrating descreased survival in arrest mice as compared to sham (initial sham $n=5$; arrest $n=13$ ). Data are expressed as mean $+/-$ SEM. ${ }^{*}=p<0.05$ 


\section{Ultrasound and Echocardiography}

Echocardiography was performed at baseline, 1 day, 1 week, and 4 weeks as previously described ${ }^{14}$. Briefly, transthoracic echocardiography was performed using the Vevo 3100 system and analyzed using VevoLab v3.2.5 (Visual Sonics). B-mode images were taken for at least 10 cardiac cycles along the parasternal long axis of the LV and end-systolic volume (ESV) and end-diastolic volumes (EDV) calculated by modified Simpson's monoplane method ${ }^{15}$. Short-axis M-mode images were obtained at the level of the papillary muscle for representative images only. Ejection Fraction (EF) was calculated from long-axis B-mode imaging as: $100 \times$ (LV EDV - LV ESV) / (LV EDV).

A cohort of mice were assessed for renal perfusion following ROSC. The ultrasound probe was oriented transversely across the abdomen at the plane of the right kidney. Doppler imaging over the renal artery evaluated the presence of blood flow every thirty seconds until sustained blood flow was noted.

\section{Serum Analysis}

After euthanasia, mice underwent cardiac puncture for collection of blood by heparinized syringe. Blood was separated by centrifugation at $2000 \times \mathrm{g}$ at $4{ }^{\circ} \mathrm{C}$ for 10 minutes and the serum was flash frozen. These samples were evaluated for blood urea nitrogen (BUN), serum creatinine, alanine aminotransferase (ALT), and creatine kinase (CK) by the Kansas State Veterinary Diagnostic Laboratories (Manhattan, KS).

\section{Tissue Histology}

Kidneys were fixed overnight in $10 \%$ formalin at $4{ }^{\circ} \mathrm{C}$ then washed with PBS and transferred to $70 \%$ ethanol at room temperature. After fixation, tissues were embedded into paraffin prior to sectioning at 4 microns by the Histology Core at the Children's Hospital of Pittsburgh. Sections were stained with hematoxylin and eosin (H\&E). Renal tubular pathology was semi-quantitatively scored (0: no injury to 4: severe injury) in terms of tubular dilatation, formation of proteinaceous casts, and loss of brush border ${ }^{16}$. Histological scoring was performed in a blinded fashion at 40x magnification on outer medullary regions of the tissue sections. Eight fields were evaluated per sample. Samples were imaged using a Leica DM 2500 microscope (Leica, Wetzlar, Germany) and LAS X software (Leica).

\section{Statistical Analysis}

Data were expressed and mean \pm standard error in all figures. $p \leq 0.05$ was considered significant for all comparisons. To determine whether sample data has been drawn from a normally distributed population, D'Agostino-Pearson test was performed. For parametric data, Student's t-test was used to compare two different groups. For nonparametric data, Mann-Whitney test was used. Survival analysis was assessed by using Kaplan-Meier and log rank (Mantel-Cox) testing. All statistical analysis was completed using Graphpad Prism 8 software (San Diego, CA). 


\section{Results}

\section{Baseline sex, weight, EF and HR are similar between groups}

19 sham and 30 arrest mice were initially utilized in this study. There was no difference in baseline weight (sham: $22.6 \pm 0.9$ g; arrest: $23.1 \pm 0.6$ g, Table 1), EF (sham: $59.8 \pm 1.5 \%$; arrest: $59.9 \pm 1.0 \%$ ) or HR (sham: $472 \pm 19 \mathrm{bpm}$; arrest: $488 \pm 11 \mathrm{bpm}$ ) between groups. A single mouse from the sham group (1/19, $5.2 \%)$ and five mice from the arrest group (5/30,16.7\%) did not achieve ROSC or died immediately after extubation. Arrest mice required an average of 1.32 minutes of CPR to achieve ROSC and were extubated after an average of 22.7 minutes (Table 1). The distribution of males and females are similar between groups (sham: 10 female, 9 male; arrest: 14 female, 16 male). While this study was not powered to examine sex-based changes amongst groups, surgical survival was not biased by sex distribution (Table 1).

Table 1. Physiologic and Surgical Characteristics of Sham and SCA Mice

\begin{tabular}{|c|c|c|c|}
\hline & Sham ( \pm SEM) & Arrest & p-value \\
\hline Age (d) & $56.8 \pm 0.7(n=18)$ & $57.7 \pm 0.6(n=25)$ & 0.34 \\
\hline Weight (g) & $22.6 \pm 0.9(n=15)$ & $23.1 \pm 0.6(n=25)$ & 0.63 \\
\hline Sex & 10 female, 9 male & 14 female, 16 male & $\mathrm{n} / \mathrm{a}$ \\
\hline $\begin{array}{c}\frac{\text { Surgical Survival }}{\text { Total }} \\
\text { Males } \\
\text { Females }\end{array}$ & $\begin{array}{c}18 / 19 \\
9 / 9 \\
9 / 10\end{array}$ & $\begin{array}{l}25 / 30 \\
14 / 16 \\
11 / 14\end{array}$ & $\mathrm{n} / \mathrm{a}$ \\
\hline CPR Duration & $\mathrm{n} / \mathrm{a}$ & $1.32 \pm 0.11(n=25)$ & $\mathrm{n} / \mathrm{a}$ \\
\hline Time to Extubation & $\mathrm{n} / \mathrm{a}$ & $22.7 \pm 0.7(n=25)$ & $\mathrm{n} / \mathrm{a}$ \\
\hline Initial Body Temp $\left({ }^{\circ} \mathrm{C}\right)$ & $35.7 \pm 0.2(n=15)$ & $35.5 \pm 0.2(n=25)$ & 0.79 \\
\hline ROSC Body Temp $\left({ }^{\circ} \mathrm{C}\right)$ & $\mathrm{n} / \mathrm{a}$ & $35.2 \pm 0.2(n=25)$ & $n / a$ \\
\hline $1 \mathrm{~h}$ Body Temp $\left({ }^{\circ} \mathrm{C}\right)$ & $35.9 \pm 0.1(n=7)$ & $35.9 \pm 0.3(n=14)$ & 0.95 \\
\hline 2 h Body Temp $\left({ }^{\circ} \mathrm{C}\right)$ & $35.8 \pm 0.1(n=7)$ & $35.2 \pm 0.3(n=13)$ & 0.18 \\
\hline 3 h Body Temp $\left({ }^{\circ} \mathrm{C}\right)$ & $35.8 \pm 0.1(n=6)$ & $33.0 \pm 0.6(n=9)$ & $<0.001$ \\
\hline 4 h Body Temp $\left({ }^{\circ} \mathrm{C}\right)$ & $35.8 \pm 0.1(n=6)$ & $32.9 \pm 0.1(n=5)$ & $<0.001$ \\
\hline $24 \mathrm{~h}$ Body Temp $\left({ }^{\circ} \mathrm{C}\right)$ & $36.6 \pm 0.2(n=7)$ & $34.8 \pm 0.4(n=10)$ & 0.03 \\
\hline Baseline HR (bpm) & $472 \pm 19(n=13)$ & $488 \pm 11(n=19)$ & 0.45 \\
\hline Baseline EF (\%) & $59.8 \pm 1.5(n=14)$ & $59.9 \pm 1.0(n=19)$ & 0.94 \\
\hline
\end{tabular}


141

142

143

144

145

146

147

148

149

150

151

152

153

154

155

156

157

158

159

160

161

162

163

164

165

166

167

168

169

170

171

172

173

\section{SCA mice have temperature and HR dysregulation after ROSC}

There were no significant differences in body temperature between groups at baseline (sham: $35.7 \pm 0.2$ ${ }^{\circ} \mathrm{C}$; arrest: $35.5 \pm 0.2^{\circ} \mathrm{C}$ ) (Table 1, Figure 1). Following extubation, mice were kept in a warmed recovery cage, and no difference was noted at 1 hour (sham: $35.9 \pm 0.1^{\circ} \mathrm{C}$; arrest: $35.9 \pm 0.3^{\circ} \mathrm{C}$ ) or 2 hours (sham: $35.8 \pm 0.1^{\circ} \mathrm{C}$; arrest: $35.2 \pm 0.3^{\circ} \mathrm{C}$ ). Arrest mice had significantly lower body temperatures once removed from the warming cage at 3 hours (sham: $35.8 \pm 0.1^{\circ} \mathrm{C}$; arrest: $33.0 \pm 0.6^{\circ} \mathrm{C}, \mathrm{p}<0.001$ ), 4 hours (sham: $35.8 \pm 0.1{ }^{\circ} \mathrm{C}$; arrest: $32.9 \pm 0.1^{\circ} \mathrm{C}, \mathrm{p}<0.001$ ) and 24 hours (sham: $36.6 \pm 0.2^{\circ} \mathrm{C}$; arrest: $34.8 \pm 0.4{ }^{\circ} \mathrm{C}, \mathrm{p}=0.03$ ). Arrest mice also had significantly lower HR one-day after SCA (sham $521 \pm 18 \mathrm{bpm}$; arrest $459 \pm 12 \mathrm{bpm}$, $p=0.007)$.

\section{SCA mice have increased 30-day mortality}

Of the post-operative survivors, a cohort from each group was evaluated for survival over a 4-week time course. At 24 hours, 100\% of sham mice survived (5 of 5) compared to $92 \%$ of arrest mice (12 of 13 , $p=0.54$ ). At 72 hours, $100 \%$ of sham mice were alive ( 5 of 5 ) compared to $46 \%$ of arrest mice ( 6 of 13 , $\mathrm{p}=0.052$ vs sham). At 4 weeks, $100 \%$ of sham mice survived ( 5 of 5 , median survival 28 days) compared to only $38 \%$ of arrest mice ( 5 of 13 , median survival 3 days, $p=0.03$; Figure 1 ). All of the SCA mouse deaths occurred within seven days following arrest.

\section{SCA mice have reduced EF, which improves over time}

Sham and arrest mice showed no difference in baseline EF (sham: $59.8 \pm 1.5 \%$; arrest: $59.9 \pm 1.0 \%$ ). One day after arrest, there was a significantly depressed EF in the arrest group (sham: $59.6 \pm 1.7 \%$; arrest: $39.9 \pm 3.0 \%, p<0.001$; Figure 2). EF of arrest mice remained significantly depressed 1 week after SCA procedure (sham: $59.6 \pm 2.3 \%$; arrest: $41.4 \pm 3.4 \%, p=0.002$ ). Four weeks after arrest, there is no significance between EF of sham and SCA groups (Figure 2).

Figure 2. Ejection Fraction and Heart Rate in Sham and SCA Mice. A) Representative M-mode tracings of a sham (top) and arrest (bottom) mouse one day after SCA, where red lines denote LV width during diastole and green lines denote systole. $B$ ) Heart rate (HR) and ejection fraction (EF) are similar between groups at baseline, but significantly depressed in SCA mice compared to sham at 1 day after arrest. C) EF is significantly decreased in SCA mice compared to sham at matched timepoints at 1 day and 1 week, but there is no significant EF change by 4 weeks. Data are expressed as mean +/-SEM. P-values: *<0.05, ** $<0.01, * * *<0.001$.

\section{SCA mice have evidence of prolonged ischemia after SCA and kidney damage at one day}

As kidney damage is a common side effect of cardiac injury ${ }^{17}$, we evaluated the duration of renal ischemia following SCA. A cohort of arrest mice $(n=10)$ were evaluated for kidney reperfusion following 
ROSC by evaluating renal artery flow. The mean duration of kidney ischemia was 20.6 minutes, with initial measurable kidney blood flow occurring on average 11.3 minutes after ROSC (Figure 3). Serum creatinine was significantly elevated in arrest mice at 1 day when compared to sham (sham: $0.36 \pm 0.06$ $\mathrm{mg} / \mathrm{dL}$; arrest: $1.52 \pm 0.22 \mathrm{mg} / \mathrm{dL}, \mathrm{p}<0.001$; Figure 3), as was serum BUN (sham: $21.5 \pm 9.9 \mathrm{mg} / \mathrm{dL}$; arrest: $156.0 \pm 39.8 \mathrm{mg} / \mathrm{dL}, \mathrm{p}=0.005$ ). Semi-quantitative scoring of tubular injury was performed at the outer medulla and was noted to be higher in arrest mice (sham: $0.15 \pm 0.05$; arrest: $3.33 \pm 0.29, p<0.0001$ ).

Figure 3. Kidney, Neurologic, and Serum Chemistry 1-day after SCA. A) Percentage of mice with recovered kidney perfusion over time since arrest $(n=10)$. Mean recovery time was $20.55 \pm 0.68 \mathrm{~min}$. B) SCA mice have increased kidney damage by semi-quantitative scoring of kidney injury in the outer medulla ( $n=5 /$ group). C) Representative H\&E stains of sham (top) and arrest (bottom) mice one-day after arrest demonstrating proteinaceous casts in renal tubules (black arrowhead) and infiltrates (red arrowheads) with glomeruli marked (blue asterisk). D) Elevated serum creatinine and BUN in SCA mice at one-day. E) Neurologic scoring at one day. F) ALT, CK, and lactate changes at one day. Data are expressed as mean +/- SEM. P-values: ${ }^{*}<0.05, * *<0.01, * * *<0.001, * * * * 0.0001$.

\section{SCA mice have diffuse tissue injury at one day}

To assess systemic damage, additional serum assays were performed at 1 day to evaluate for liver damage (ALT), muscle damage (CK), tissue ischemia (lactate), and neurologic function. These assays were notable for a significant increase in ALT (sham: 47.6 $\pm 4.7 \mathrm{U} / \mathrm{L}$; arrest: $135.6 \pm 37.3 \mathrm{U} / \mathrm{L}, \mathrm{p}=0.047$; Figure 3) in arrest mice compared to sham. No significant changes were noted to serum CK (sham: $1244 \pm 252 \mathrm{U} / \mathrm{L}$; arrest: $1811 \pm 570 \mathrm{U} / \mathrm{L}, \mathrm{p}=0.36$ ) or normalized serum lactate (sham: $1.00 \pm 0.06$; arrest: $1.90 \pm 0.64, p=0.15)$. Brief neurologic testing was performed as previously reported ${ }^{11}$ on 14 sham and 17 arrest mice one day after SCA (Table 2). Two of the arrest mice were noted to have hind-leg ataxia and one mouse had sluggish movement; however, there was no significant difference in neurologic testing between the groups (sham: score 12.0 \pm 0 ; arrest: score 11.8 $\pm 0.1, p=0.13$; Figure 3).

Table 2. 12-point Neurologic Function Assessment for One-Day Sham and SCA Mice

\begin{tabular}{|l|c|}
\hline \multicolumn{2}{|c|}{ Neurological Function } \\
\hline Level of Consciousness & 0 \\
\hline No Tail Pinch Reflex & 1 \\
\hline Weak Tail Pinch Reflex & 2 \\
\hline Normal Tail Pinch Reflex & 0 \\
\hline Corneal Reflex & 1 \\
\hline No Blink & 2 \\
\hline Delayed Blink & \\
\hline Normal Blink & \\
\hline Respiration & 0 \\
\hline Irregular & \\
\hline
\end{tabular}




\begin{tabular}{|l|c|}
\hline Decreased Frequency with Normal Pattern & \multicolumn{2}{|c|}{2} \\
\hline Normal Frequency and Pattern & 0 \\
\hline Righting Reflex & 1 \\
\hline No Righting & 2 \\
\hline Sluggish Righting & \\
\hline Rapid Righting & 0 \\
\hline Coordination & 1 \\
\hline No Movement & 2 \\
\hline Some Ataxia & \\
\hline Normal Coordination & \\
\hline Activity & \\
\hline No Spontaneous Movement & 12 \\
\hline Sluggish Movement & 2 \\
\hline Normal Movement & 12 \\
\hline Total Possible Score & \\
\hline
\end{tabular}

\section{Discussion}

201 In this study, we modified the mouse model of SCA described by Hutchens et al. ${ }^{9}$ by delivering $\mathrm{KCl}$ directly into the LV cavity under ultrasound guidance rather than IJ cannulation. This delivery method causes immediate onset of asystole after $\mathrm{KCl}$ delivery in a highly controlled, easily visualized, and easily adoptable manner. Pre-clinical models of SCA are rarely performed in the mouse despite a large number of advantages of the murine model, including rapid development, low maintenance cost, and the opportunity for genetic manipulation ${ }^{6,7}$. The low utilization of the murine model is likely attributable to surgical difficulties related to animal size. Groups that have embraced the mouse model of SCA almost uniformly rely on intravenous delivery of $\mathrm{KCl}$ for induction of cardiac arrest, but have utilized various durations of arrest (typically 4-16 minutes). These reports all use venous access either through the jugular or femoral veins for drug delivery. Establishing reliable venous access in the mouse remains a

212 Our model spares the use of major vessels for drug delivery by using direct LV introduction under 213 ultrasound, resulting in rapid procedure times, typically around 30 minutes from anesthesia induction to 214 extubation, with low surgical mortality (16.7\% of SCA mouse surgical mortality, Table 1). Ultrasound215 guided catheter placement has already become a staple of hospital care for many clinicians, allowing 216 physicians and researchers to easily transfer a known skill set into a translational model of SCA ${ }^{18,19}$.

217 Additionally, the destruction of major veins by cannulation in the traditional mouse model may limit 
venous drainage post-operatively, which may affect both neurologic and cardiac performance. Our method avoids both venous access and blockage. Further, ultrasound utilization allows for continual non-invasive monitoring of cardiac function throughout the arrest, resulting in precise monitoring of cardiac arrest duration. Previously published models that utilize only ECG as an indicator of ROSC may falsely register pulseless electrical activity as a return of circulation, which may erroneously measure ischemic duration. Other models utilize an LV pressure catheter to accurately record restoration of cardiac flow; however, this requires the placement of an additional invasive canula. In the current report, the rapid procedure time, high survival, reduced surgical skill required, and venous sparing by this technique are highly advantageous over the traditional model.

Of the 30 mice that underwent arrest in this study, 25 survived the arrest and achieved ROSC, resulting in a relatively low mortality rate $(16.7 \%)$ for the procedure (Table 1$)$. This is a modest improvement over the $20 \%$ surgical mortality in the venous $\mathrm{KCl}$ mouse model described by Hutchens et al. ${ }^{9}$ and the $27 \%$ mortality in a ventricular fibrillation mouse model described by Chen et al. ${ }^{8} \mathrm{~A}$ subset of mice was studied for up to 4 weeks to assess long-term survival. At 72 hours, 6 of 13 arrest mice (46\%) survived, which is in line with comparable recent studies publishing between 10 and $45 \%$ survival at 72 hours ${ }^{20-22} .5$ of 13 mice (38\%) survived for the entire duration of the study (Figure 1).

After one day, EF in SCA mice is significantly decreased from $59.9 \%$ at baseline to $39.9 \%$. These values are in-line with previously published one day EFs and are likely attributable to cardiac stunning ${ }^{21}$. EF remains significantly decreased at one week (41.4\%), with improvement at four weeks (49.8\%, Figure 2). These values and their relative improvement are similar to those observed in humans following cardiac arrest in the absence of coronary disease, as evidenced by a case series of cardiac arrest survivors, which noted 1 day EFs of 38\%, 1 week EFs of $44 \%$, and 2-3 week EFs of $50 \%{ }^{23}$.

Maintenance of body temperature is critically important to neurologic outcomes following SCA ${ }^{24-26}$. We maintained body temperatures with active heating for 2 hours after arrest, but body temperatures fell significantly after active heating was stopped, which is consistent with post-arrest changes in humans ${ }^{27}$. The SCA mice continued to show significant temperature dysregulation and depressed HR at one day (Figure 1, Table 1). We were unable to demonstrate significant neurologic deficit 24 hours after arrest by utilizing a well-established, 12-point examination ${ }^{11}$. Delayed, spontaneous hypothermia is known to be neuroprotective in other rodent cardiac arrest models and may explain the paucity of neurological injury noted ${ }^{28}$. We only noted ataxia in two mice and lethargy in one mouse following SCA, with no observable deficits in sham mice. While some groups are able to demonstrate neurologic injury with as little as 6minutes of cardiac arrest ${ }^{29}$, others have required extended arrest time of 12-14 minutes to detect neurologic changes ${ }^{10,30}$. The technique described in this paper would be easily modified to allow for prolonged arrest time to study neurologic insult.

Mouse SCA models have been utilized to as a clinically-relevant model of both acute kidney injury 31,32 (one day after arrest) and chronic kidney disease (seven weeks after arrest, attributed to prolonged inflammation after reperfusion) ${ }^{32}$. We show that our model of SCA similarly develops markers of AKI, as evidenced by elevated serum creatinine, BUN, and tubular damage 1 day after arrest (Figure 3). Many of the peripheral kidney tubules are anucleated one-day after arrest, which is a marker of nephrotic damage in mice. Kidney injury is not typically apparent with 8 minutes of direct ischemia, which typically require 15-20 minutes for the development of focal injury ${ }^{33}$. By utilizing doppler ultrasonography of the renal artery, we found that the kidney did not receive measurable perfusion until 11.25 minutes after 
bioRxiv preprint doi: https://doi.org/10.1101/2020.07.27.222695; this version posted July 27, 2020. The copyright holder for this preprint (which was not certified by peer review) is the author/funder, who has granted bioRxiv a license to display the preprint in perpetuity. It is made available under aCC-BY 4.0 International license.

260 ROSC, for a total mean ischemia duration of 20.55 minutes, resulting in kidney ischemia times consistent 261 with established direct ischemia reperfusion injury models (Figure 3) 34,35 .

262 Finally, our model suggests the presence of global ischemic injury following SCA. ALT, a non-specific 263 marker of liver injury, is significantly elevated one-day after SCA (Figure 3). However, there are non264 significant trends towards increased CK, a non-specific marker of muscle degradation, and serum lactate 265 levels in the SCA mice. These changes are consistent with the markers of secondary ischemic damage 266 seen in post-cardiac arrest patients. We anticipate that these changes could become significant with 267 prolonged arrest duration, but at the cost of increased mortality. Further evaluation of this multiple 268 organ damage and the degree to which each organ system is involved may be an important step toward 269 improving recovery and guiding post-cardiac arrest interventions. 
bioRxiv preprint doi: https://doi.org/10.1101/2020.07.27.222695; this version posted July 27, 2020. The copyright holder for this preprint (which was not certified by peer review) is the author/funder, who has granted bioRxiv a license to display the preprint in perpetuity. It is made available under aCC-BY 4.0 International license.

\section{Conclusions}

272 We demonstrate a novel mouse model of SCA that utilizes direct LV injection of $\mathrm{KCl}$ under ultrasound

273 guidance that allows for rapid and reliable arrest with low surgical mortality. This model develops

274 significant cardiac, kidney, and liver injury at one day and a trend towards neurologic injury. Time of 275 injury but can be easily adapted to achieve neurologic insult. This model lowers the barrier to entry for 276 establishing a mouse model of SCA, which will help researchers investigate the mechanisms underlying 277 SCA mortality. 


\section{References}

1. Benjamin EJ, Muntner P, Alonso A, et al. Heart Disease and Stroke Statistics - 2019 Update: A Report From the American Heart Association. Circulation. 2019;139:e56-e528.

2. Daya MR, Schmicker RH, Zive DM, et al. Out-of-hospital cardiac arrest survival improving over time: Results from the Resuscitation Outcomes Consortium (ROC). Resuscitation. 2015;91:108115.

3. Reynolds JC, Frisch A, Rittenberger JC. Out-of-Hospital Cardiac Arrest: When Should We Change to Novel Therapies? Circulation. 2014;128(23):2488-2494.

4. Barouxis D, Chalkias A, Syggelou A, lacovidou N, Xanthos T. Research in human resuscitation: what we learn from animals. J Matern Neonatal Med. 2012;25(S5):44-46. d

5. Vognsen M, Fabian-Jessing BK, Secher N, et al. Contemporary animal models of cardiac arrest: A systematic review. Resuscitation. 2017;113:115-123.

6. Vandamme TF. Use of rodents as models of human diseases. J Pharm BioAllied Sci. 2014;6(1):2-9.

7. Papadimitriou D, Xanthos T, Lelovas P, Perrea P. The Use of Mice and Rats as Animal Models for Cardiopulmonary Resuscitation Research. Lab Anim. 2008;24:265-276.

8. Chen M, Liu T, Xie L, et al. A simpler cardiac arrest model in the mouse. Resuscitation. 2007;75:372-379.

9. Hutchens M, Traystman R, Fujiyoshi T, Nakayama S, Herson P. Normothermic Cardiac Arrest and Cardiopulmonary Resuscitation: A Mouse Model of Ischemia-Reperfusion Injury. Jove. 2011;54.

10. Dezfulian C, Shiva S, Alekseyenko A, et al. Nitrite therapy after cardiac arrest reduces reactive oxygen species generation, improves cardiac and neurological function, and enhances survival via reversible inhibition of mitochondrial complex I. Circulation. 2009;120(10):897-905.

11. Abella BS, Zhao D, Alvarado J, Hamann K, Hoek TL Vanden, Becker LB. Intra-Arrest Cooling Improves Outcomes in a Murine Cardiac Arrest Model. Circulation. 2004;109:2786-2791.

12. Ikeda K, Marutani E, Hirai S, Wood ME, Whiteman M, Ichinose F. Mitochondria-targeted hydrogen sulfide donor AP39 improves neurological outcomes after cardiac arrest in mice. Nitric Oxide. 2015;49:90-96.

13. Xu L, Zhang Q, Zhang QS, Li Q, Han JY, Sun P. Improved Survival and Neurological Outcomes after Cardiopulmonary Resuscitation in Toll - like Receptor 4 - mutant Mice. Chin Med J (Engl). 2015;128(19):1-6.

14. Rutledge C, Cater G, Mcmahon B, et al. Commercial 4-dimensional echocardiography for murine heart volumetric evaluation after myocardial infarction. 2020;5:1-10.

15. Lang RM, Badano LP, Mor-avi V, et al. Recommendations for Cardiac Chamber Quantification by Echocardiography in Adults : An Update from the American Society of Echocardiography and the European Association of Cardiovascular Imaging. J Am Soc Echocardiogr. 2015;28(1):1-39.e14.

16. Chiba T, Peasley KD, Cargill KR, et al. Sirtuin 5 Regulates Proximal Tubule Fatty Acid Oxidation to Protect against AKI. 2019:1-15.

17. Yanta J, Guyette FX, Doshi AA, et al. Renal dysfunction is common following resuscitation from 
out-of-hospital cardiac arrest. Resuscitation. 2013;84(10):1371-1374.

18. Schmidt GA, Maizel J, Slama M. Ultrasound-guided central venous access : what's new? Intensive Care Med. 2014:14-16.

19. Biasucci DG, La Greca A, Scoppettuolo G, Pittiruti M. What's really new in the field of vascular access? Towards a global use of ultrasound. Intensive Care Med. 2015:10-12.

20. Id JL, Zhu X, Id HW, et al. Akt1-mediated CPR cooling protection targets regulators of metabolism, inflammation and contractile function in mouse cardiac arrest. PLoS One. 2019;14(8):1-18.

21. Piao L, Fang Y, Hamanaka RB, et al. Suppression of Superoxide-Hydrogen Peroxide Production at Site I. Crit Care Med. 2020;(1):133-140.

22. Piao L, Ph D, Varughese J, Archer SL. Inhibition of the Mitochondrial Fission Protein Drp1 Improves Survival in a Murine Cardiac Arrest Model. Crit Care Med. 2016;43(2):1-22.

23. Ruiz-bail M, Aguayo E, Hoyos $D$, et al. Reversible myocardial dysfunction after cardiopulmonary resuscitation. 2005;66:175-181.

24. Abella BS, Zhao D, Alvarado J, Hamann K, Vanden Hoek TL, Becker LB. Intra-arrest cooling improves outcomes in a murine cardiac arrest model. Circulation. 2004;109(22):2786-2791.

25. Nolan JP, Berg RA, Bernard S, et al. Intensive care medicine research agenda on cardiac arrest. Intensive Care Med. 2017;43(9):1282-1293.

26. Sandroni C, Cavallaro F, Callaway CW, et al. Predictors of poor neurological outcome in adult comatose survivors of cardiac arrest : A systematic review and meta-analysis . Part 2 : Patients treated with therapeutic hypothermia. Resuscitation. 2013;84(10):1324-1338.

27. The Hypothermia After Cardiac Arrest Study Group. Mild Therapeutic Hypothermia to Improve the Neurologic Outcome after Cardiac Arrest. N Engl J Med. 2002;346(8):549-556.

28. Hickey RW, Ferimer H, Alexander HL, et al. Delayed, spontaneous hypothermia reduces neuronal damage after asphyxial cardiac arrest in rats. Crit Care Med. 2000;28(10):3511-3516.

29. Yong Y, Guo J, Zheng D, et al. Electroacupuncture pretreatment attenuates brain injury in a mouse model of cardiac arrest and cardiopulmonary resuscitation via the AKT / eNOS pathway. Life Sci. 2019;235:116821.

30. Kofler J, Hattori K, Sawada M, et al. Histopathological and behavioral characterization of a novel model of cardiac arrest and cardiopulmonary resuscitation in mice. J Neurosci Methods. 2004;136(1):33-44.

31. Burne-taney MJ, Kofler J, Yokota N, et al. Acute renal failure after whole body ischemia is characterized by inflammation and T cell-mediated injury. Am J Physiol Ren Physiol. 2003;285:F87-F94.

32. Matsushita K, Saritas T, Eiwaz MB, et al. The acute kidney injury to chronic kidney disease transition in a mouse model of acute cardiorenal syndrome emphasizes the role of inflammation. Kidney Int.:10-17.

33. Heyman SN, Rosen S, Rosenberger C. Animal models of renal dysfunction : acute kidney injury. Expert Opin if Drug Discov. 2009;4(6):629-641. 
bioRxiv preprint doi: https://doi.org/10.1101/2020.07.27.222695; this version posted July 27, 2020. The copyright holder for this preprint (which was not certified by peer review) is the author/funder, who has granted bioRxiv a license to display the preprint in perpetuity. It is made available under aCC-BY 4.0 International license.

34. Shanley PF, Rosen MD, Brezis M, Silva P, Epstein FH, Rosen S. Topography of focal proximal tubular necrosis after ischemia with reflow in the rat kidney. Am J Pathol. 1986;122(3):462-468.

35. Glaumann B, Glaumann H, Berezesky IK, Trump BF. Studies on the pathogenesis of ischemic cell injury. II. Morphological changes of the pars convoluta (P1 and P2) of the proximal tubule of the rat kidney made ischemic in vivo. Virchows Arch B, Cell Pathol. 1975;19(4):281-302. 


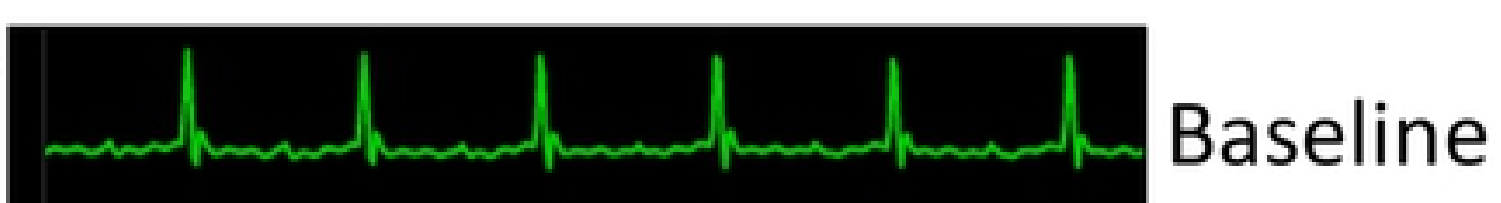

Needle

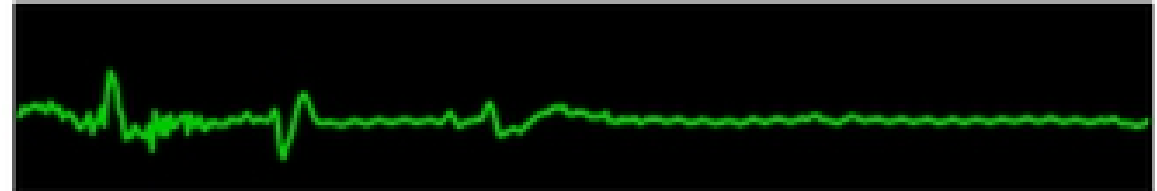

$\mathrm{KCl}$
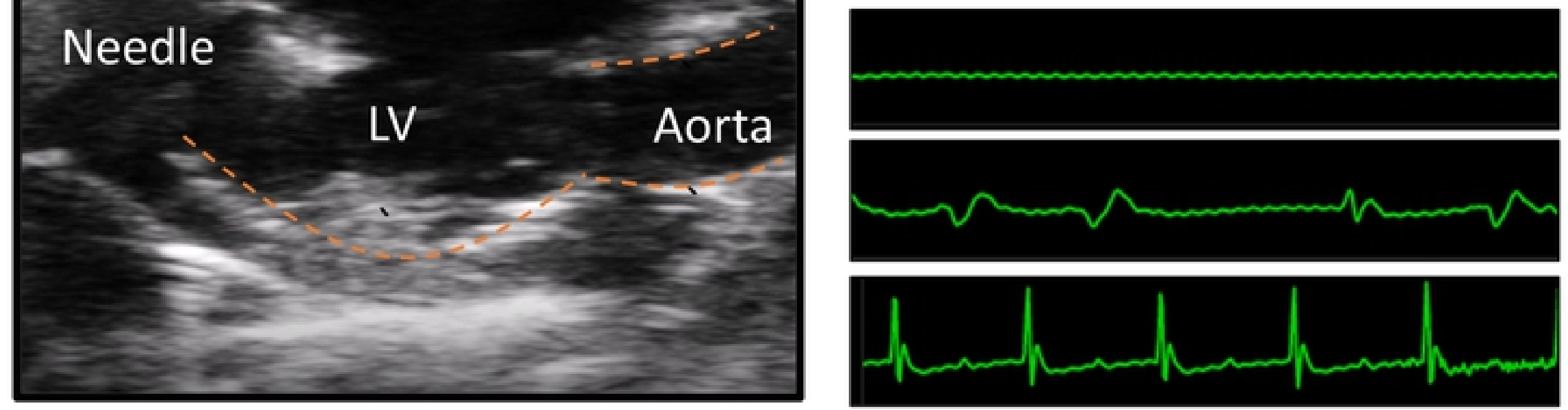

Asystole

ROSC

C

Intubation \&

Epinephrine Injection

Ventilation

Ventilation \&

Direct LV KCl Injection

Compressions

Recovery

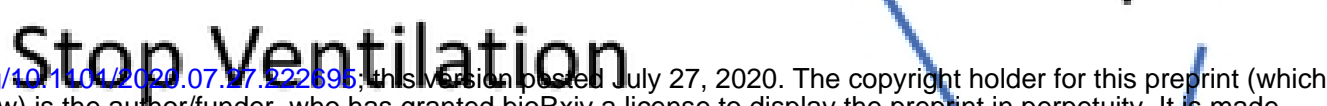

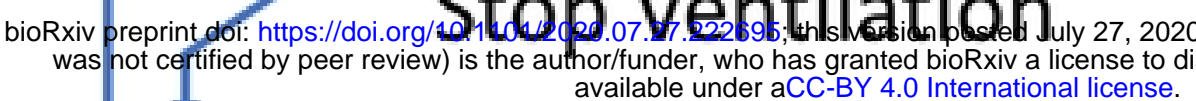

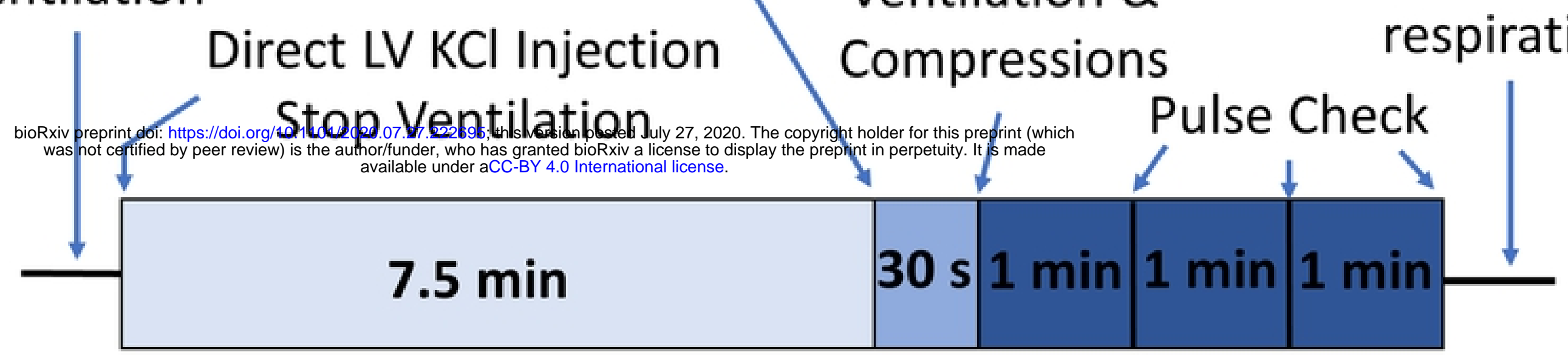

D

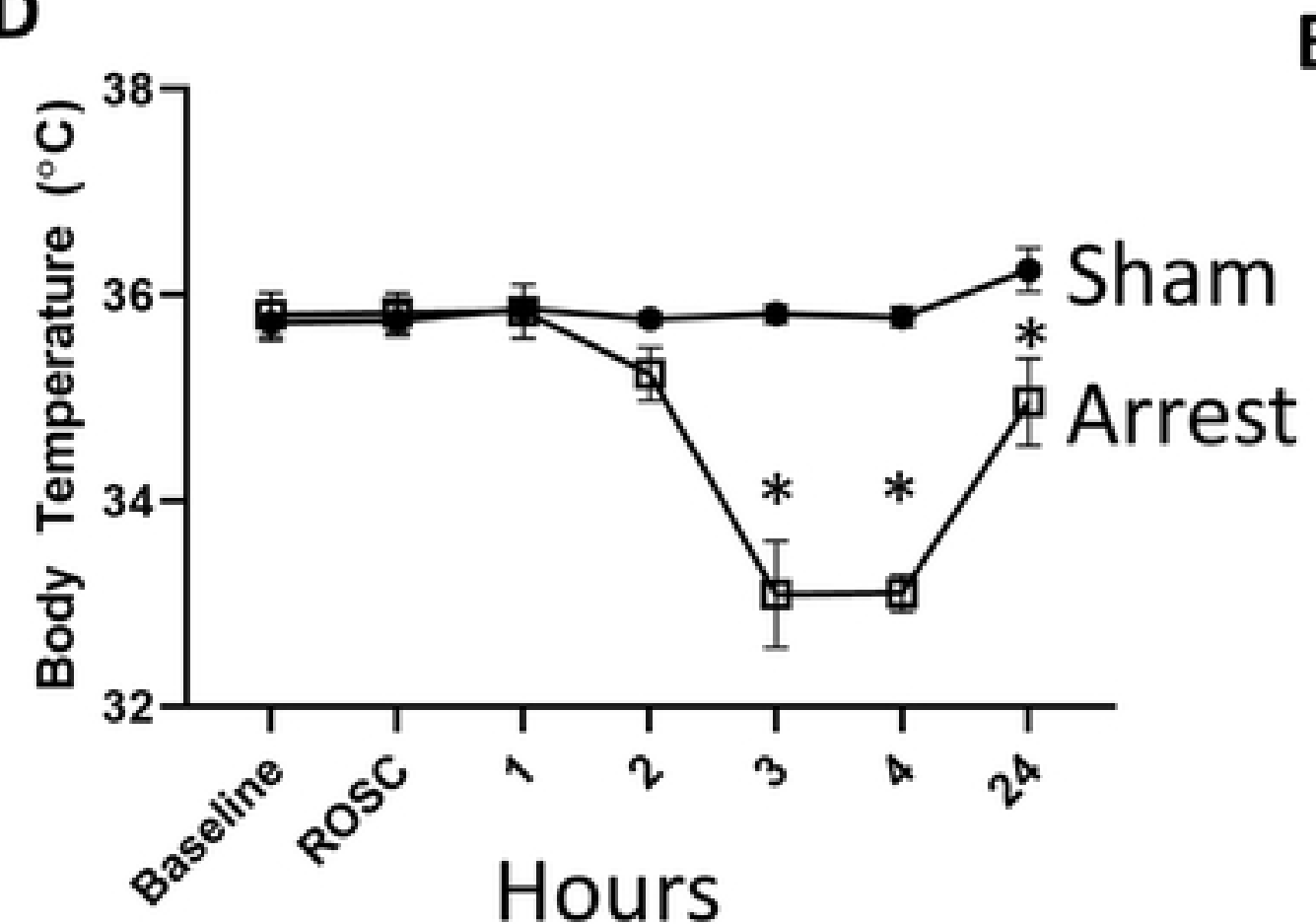

E

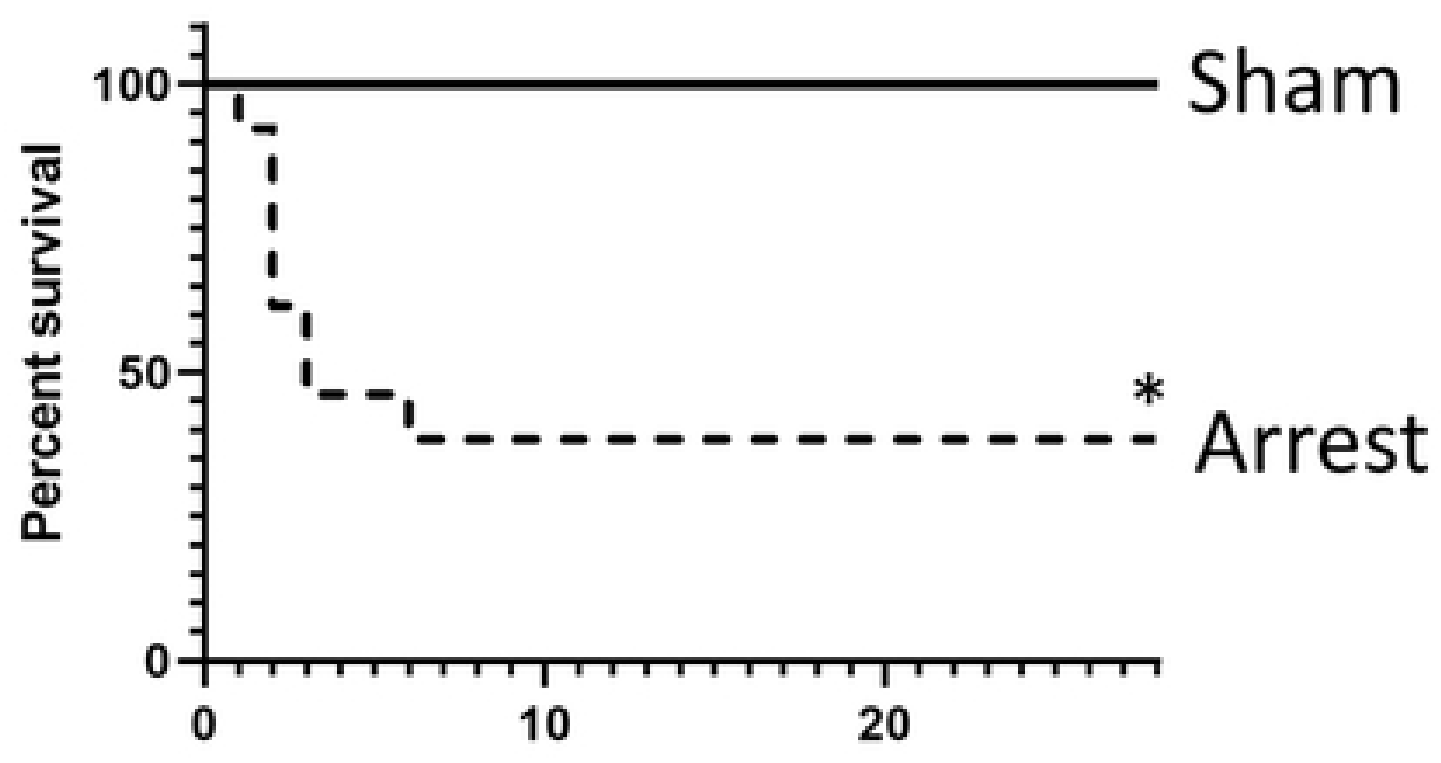

Days

Figure 1 


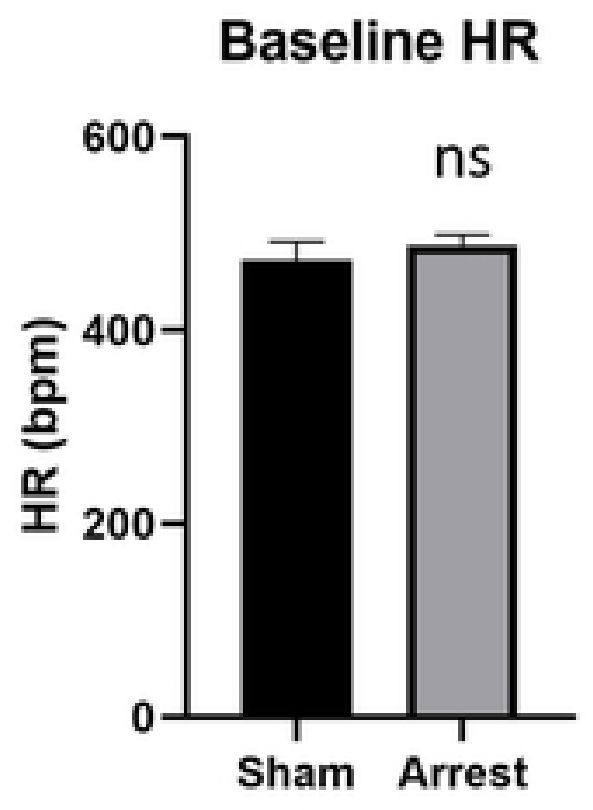

1 day HR
Baseline EF

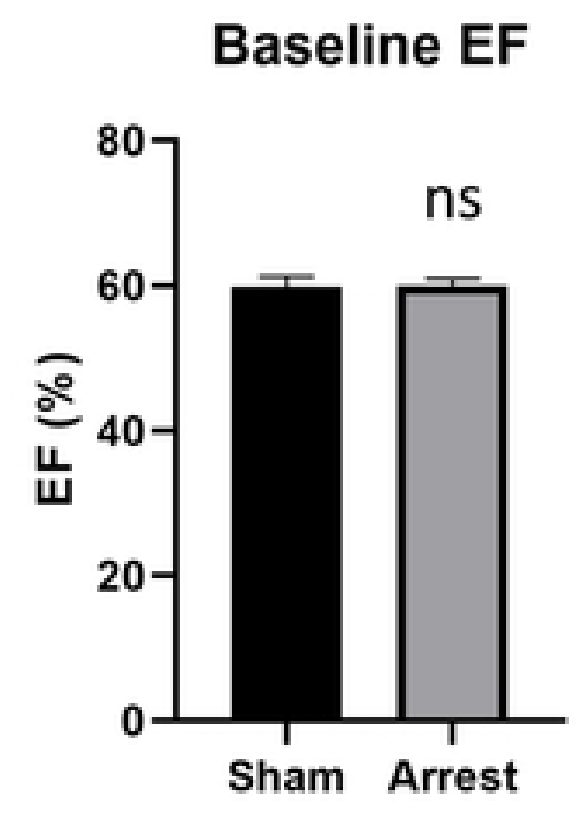

1 day EF

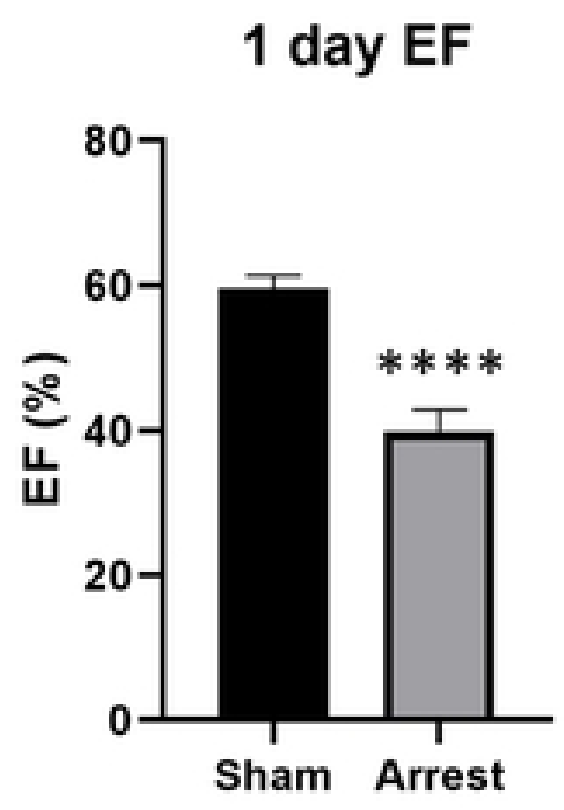

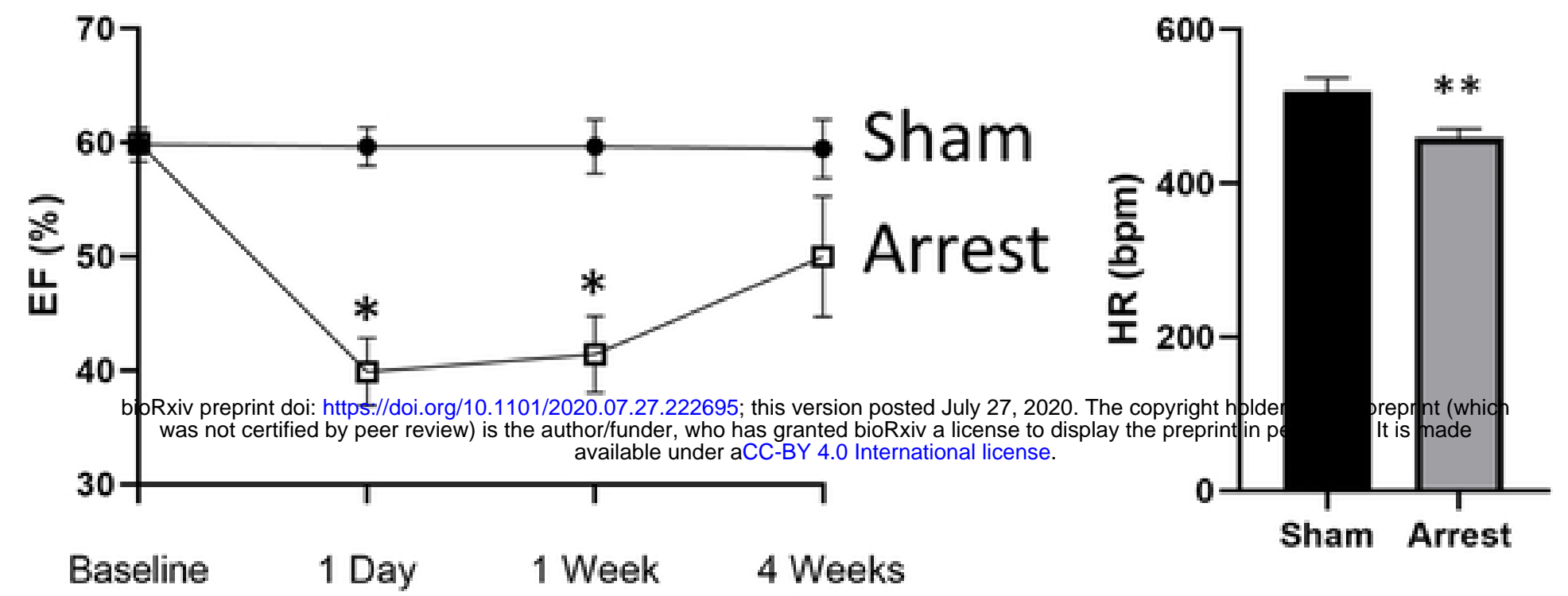

C

Figure 2 
